Open Access

\title{
Properties of Asphalt Binders with the Residue from Pyrolysis of Biomass as the Warm Mix Additive
}

\author{
Tew Chin Wei ${ }^{1}$, Tye Ching Thian ${ }^{1 *}$, Meor Othman Hamzah² and Babak Golchin ${ }^{3}$ \\ ${ }^{\prime}$ School of Chemical Engineering, Engineering Campus, UniversitiSains Malaysia, 14300 NibongTebal, SeberangPerai Selatan, Penang, Malaysia \\ ${ }^{2}$ School of Civil Engineering, Engineering Campus, UniversitiSains Malaysia, 14300 NibongTebal, SeberangPerai Selatan, Penang, Malaysia \\ ${ }^{3}$ Department of Civil Engineering, Ahar Branch, Islamic Azad University, Ahar, Iran
}

\section{Article Info \\ *Corresponding author: \\ Ching Thian Tye \\ Associate Professor \\ School of Chemical Engineering \\ Universiti Sains Malaysia \\ 14300 Nibong Tebal \\ Seberang Perai Selatan \\ Penang, Malaysia \\ E-mail: chcttye@usm.my}

Received: March 8, 2017

Accepted: March 16, 2017

Published: March 22, 2017

Citation: Tan CW, Tye CT, Hamzah MO, Golchin B. Properties of Asphalt Binders with the residue from pyrolysis of Biomass as the Warm Mix Additive. Int J Petrochem Res. 2017; 1(1): 1-5.

doi: 10.18689/ijpr-1000101

Copyright: () 2017 The Author(s). This work is licensed under a Creative Commons Attribution 4.0 International License, which permits unrestricted use, distribution, and reproduction in any medium, provided the original work is properly cited.

Published by Madridge Publishers

\begin{abstract}
Asphalt is a complex mixture of hydrocarbons. Recently, a series of substances have been used as an additive in order to change the asphalt's properties especially in the road pavement engineering. This paper presents the properties changes of two asphalt binders: AC 80/100 and SBS modified binders as the results of using residue from pyrolysis of biomass as the warm mix additive. The resulted asphalt binders were evaluated over a series of analyses including viscosity tests, dynamics shear rheological tests, gel permeation chromatography and asphaltenes content analysis. Generally, it could be concluded that residue from pyrolysis of biomass has a potential to be a warm mix additive in term of viscosity reduction under certain conditions. It has also sufficient Superpave rutting resistance at temperature as high as $64^{\circ} \mathrm{C}$.
\end{abstract}

Keywords: Warm mix asphalt; biomass; asphaltene; viscosity.

\section{Introduction}

Hot mix asphalt was the most common and widely used technology in the pavement construction. The mixing of aggregates and asphalt cement are normally carried out at temperature higher than $150^{\circ} \mathrm{C}$. Warm mix asphalt (WMA) technology is an innovation developed with the aim of reducing the high temperature requirements for manufacturing and laying of asphalt mixes [1]. WMA additive is a substance that is blended into the asphalt binders or directly introduced into the asphalt plant's drum that improves the process of manufacturing and paving asphalt by significantly reducing the temperatures down to $40^{\circ} \mathrm{C}$ [1] [2] [3]. WMA helps to reach a more sustainable and less carbon intensive processes and products.

Recently, significant attention has being given to new and innovative materials, which can act as WMA additive. For instance, Jamshidi et al. [4] evaluated the rheological properties of unaged and aged asphalt binders incorporating various Sasobit and Rediset contents at high and intermediate temperatures. Their results showed that rheological properties of binders significantly depend on the binder source, additive type and content. Later, an optimization method was used in selecting an appropriate binder content, additive content and compaction temperature for fabrication of WMA mixtures [5]. In 2016, Kakar et al. [6] evaluated the influence of a surfactant based warm additive named Cecabase on the rheological properties of binders and mixtures. The results showed that this additive has no effect on the binder rheology but it improves the workability and compactibility of the asphalt mixtures. In another study, Gungat et al. [7] characterized the influence of a warm wax additive named RH-WMA on rhelogical 
properties of binders containing high amount of reclaimed binders. Obtained results showed that this additive reduces the viscosity of binders as well as improves the elasticity of the binders. There were almost 20 WMA technologies being marketed in the United States from 2005 to 2010 [8].These WMA processes are generally categorized into three: foaming process that uses water containing technology or water-based technology, organic additives and chemical additives [1] [9]. All having the same goal, which is to reduce the binder viscosity, to enhance the coating and workability of the mix, lower energy consumption and reduce emission [9]. Rubio et al. [1] have presented a detailed review of the WMA in 2012.

Organic additives such as Fischer-Tropsch wax, Montan wax, and fatty acid amide wax with the trade name of Asphaltan B, Sasobit and Licomont BS were extensively used as WMA additives in laboratory studies [1]. In literatures, the most common organic additive used is wax. Viscosities of binders are reduced when wax is melted in the mix [3] [9]. One of the important aspects of waxes is to be resistant at service temperatures. Research which has done on the beneficial effects of wax on asphalt showed that it is critically dependent on the chemical structure of the waxes [10]. The length of hydrocarbon in wax can affect the melting temperature of waxes. Waxes that are selected to be used as WMA additives are chosen based on their higher melting point above the service temperature and their ability to mix with asphalt [10]. The waxes used are usually high molecular hydrocarbon chains with a melting point about $80^{\circ} \mathrm{C}$ to $120^{\circ} \mathrm{C}$ and are able to modify the virgin binder's properties [11].

This paper introduces a new chemical material, residue from pyrolysis of biomass (RPB), which may have a potential to be used as WMA additive. The residue is a condensed volatile matter in the pyrolysis process of biomass for activated carbon. RPB could be a suitable material to be used in asphalt binder because of its low price and it is easy to obtain. Since RPB is an organic based hydrocarbon as the wax, it could have similar effects as the wax on asphalt binder. In this regard, the effects of this material as an additive on different asphalt binders were investigated. There was a series of analytical tests on properties carried out in order to study the properties changes of asphalt binders after adding different amounts of RPB.

\section{Experimental}

\section{WMA binder mixture preparation}

Two types of asphalt binder were used in the present study which were: Styrene-Butadiene-Styrene (SBS) asphalt binder and asphalt cement according to penetration grade 80/100 (AC 80/100) provided by Shell Corp., Malaysia. The additive used was residue from pyrolysis of biomass (RPB) for activated carbon obtained from the relevant experiments in lab. For binder mixture preparation, a Silverson L4RT blender was used to blend the binder and additives. First, the SBS binder was heated up to $180^{\circ} \mathrm{C}$ in an oven for 3 hours. Then, $200 \mathrm{~g}$ of heated binder with the required amount of additive
(1-3 wt\%) were loaded into the blender's container which was also preheated to $180^{\circ} \mathrm{C}$. The blender's container together with the heater was then placed under the high shear blender propeller. A thermostat was also placed into the hot binder. The blending was done at $3000 \mathrm{rpm}$ for 15 minutes to ensure the additive has properly dissolved and formed a homogenous phase with the binder. The similar sample preparation procedure was followed when using AC80/100 as the asphalt binder except the heating and operating temperature was changed to $140^{\circ} \mathrm{C}$.

\section{Thermal analysis}

Thermal analysis was performed using a Perkin Elmer Thermal Analyzer, model STA 6000 under nitrogen (99.9995\%) atmosphere, sample mass around $10 \mathrm{mg}$, with a constant heating rate of $10^{\circ} \mathrm{C} / \mathrm{min}$, heated from room temperature to $600^{\circ} \mathrm{C}$. The nitrogen flow during the experiments was $20 \mathrm{ml} /$ min. The mass versus temperature curves were used to evaluate the thermal stability of binders respectively.

\section{Asphaltenes Analysis}

This analysis gives a measure of the percentage of asphaltene content in the binder. The method was a typical asphaltenes analysis test [12] for heavy oil. For each sample, $2 \mathrm{~g}$ of liquid binder sample with $2 \mathrm{ml}$ of toluene (Reagent grade, Fisher Scientific) was dissolved in a $100 \mathrm{ml}$ beaker. Then, the sample was mixed with $80 \mathrm{ml}$ of $\mathrm{n}$-pentane (Analytical reagent grade, Fisher Scientific). The sample was kept in dark and shaken for 5 minutes in every 30 minutes over a 2 hours period. The precipitated formed was filtered through a medium pore (10-15 $\mu \mathrm{m})$ Buchner filter funnel under slight vacuum. The precipitate was washed with $n$-pentane and dried in an oven at $110^{\circ} \mathrm{C}$. The asphaltenes content was calculated by the following equation:

$$
\text { Asphathenes content }(w t \%)=\left[\frac{\text { (weight of precipitate) }}{\text { weight of initial binder }}\right] \times 100 \%
$$

\section{Rotational viscometer (RV) test}

One of the most important properties to be considered in asphalt binder production is the viscosity of asphalt binder at high temperature. It describes the ability to pump an asphalt binder in a plant and the ability to coat the aggregates in asphalt concrete binders before compacting into new pavement surface [13]. A Model DV-II + rotational viscometer by Brookfield Engineering Inc. was used for the viscosity measurement of the binder with additive. The procedure used was according to AASHTO T 316 (Standard Method of Test for Viscosity Determination of Asphalt Binder Using Rotational Viscometer).

\section{Dynamic Shear Rheometer (DSR) test}

DSR test was used to determine the complex modulus $\left(G^{*}\right)$ and phase angle $(\delta)$ of the asphalt binder. The performance of asphalt binder was investigated in terms of rutting resistance $\left(G^{*} / \sin \delta\right)$. The DSR test was performed by a Haake Rheo Stress 6000 DSR Rheometer. The DSR test was carried out according to the ASTM D7175 procedures. 


\section{Results and Discussion Chemical properties of asphalt binders}

AC80/100 binder is the most common type of asphalt binder used in Malaysia for road construction [14]. Meanwhile, SBS polymer modified binder with improvement in terms of rutting resistance, thermal cracking and fatigue damage [15], which is costly, is often used at the airport pavement. Elemental analysis of AC 80/100 and SBS polymer modified binders showed that the $\mathrm{H} / \mathrm{C}$ ratio were 1.83 and 2.49 , respectively. By referring to Altgelt [16], typical $\mathrm{H} / \mathrm{C}$ atomic ratio of bitumen asphalt is usually between narrow ranges of 1.40-1.90. Therefore, the asphalt binders used were at the lighter end of the range. The sulphur contents were $7.7 \mathrm{wt} \%$ and $4.7 \mathrm{wt} \%$ for AC 80/100 and SBS polymer modified binders, respectively. Results were high as expected which is common for the asphalt. Therefore, it will benefit a lot especially in terms of sulphur emission to the air if the mixing and working temperature of the asphalt binder for pavement construction can be reduced.

Figure 1(a) shows the thermogravimetric curve for AC $80 / 100$ binder. From the figure, the rate of weight loss starts to be significant at temperature $385^{\circ} \mathrm{C}$ at $87.6 \mathrm{wt} \%$. The weight dropped quickly to a plateau at around $490^{\circ} \mathrm{C}$ and stayed almost flat. This indicated that $87.6 \mathrm{wt} \%$ of AC $80 / 100$ binder is unstable at temperature higher than $385^{\circ} \mathrm{C}$. Sample left is remained constant at $20.6 \mathrm{wt} \%$ between $490^{\circ} \mathrm{C}$ and $552^{\circ} \mathrm{C}$. The residue can be carbon residue as well as the materials with much higher boiling point than $552^{\circ} \mathrm{C}$.
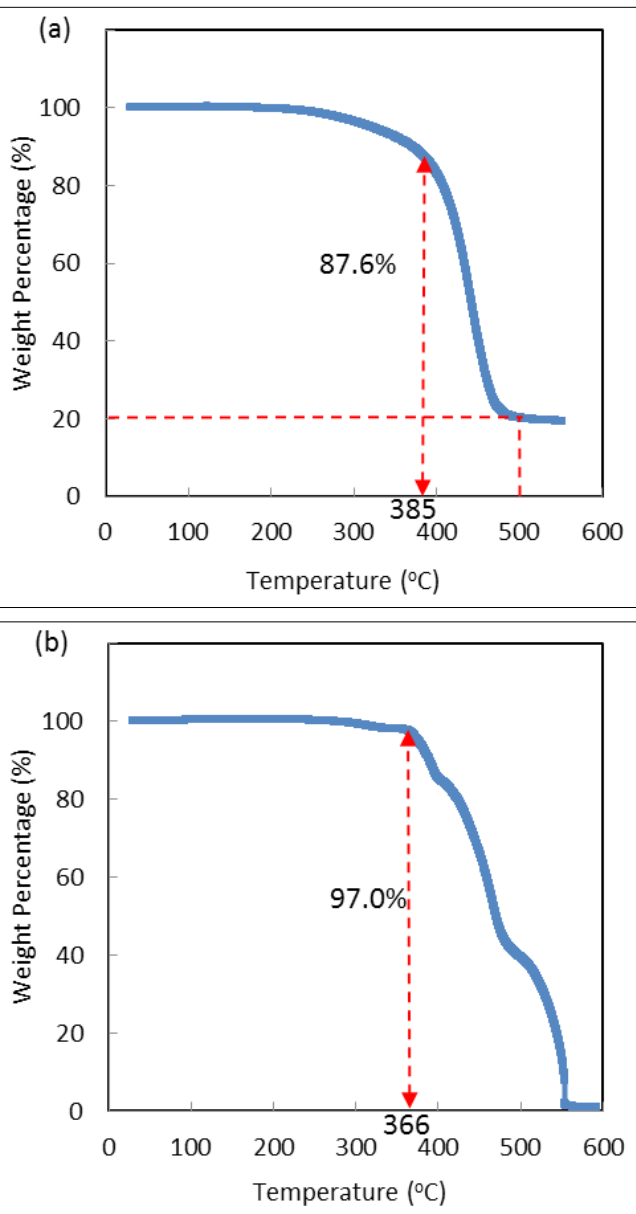

Figure 1. Thermogravimetric curve of (a) AC 80/100 binder and (b) SBS asphalt binder
From the thermogravimetric curve as shown in Figure 1(b), SBS asphalt binder was found to be thermally stable until a temperature of $366^{\circ} \mathrm{C}$ after which the weight started to drop significantly to almost zero at $550^{\circ} \mathrm{C}$. Based on the graph, it indicates that this binder is slightly more thermally stable compared to AC 80/100 up to $366^{\circ} \mathrm{C}$. Sample left was remained constant at $1.15 \mathrm{wt} \%$ after $593^{\circ} \mathrm{C}$. The residue left was mainly the carbon residue. The low level of carbon residue in SBS asphalt binder might be due to the added styrene-butadiene-styrene block copolymer, which modified the bonding within the molecules in asphalt which reduced the formation of carbon residue at high temperature.

RPB was chosen as potential warm mix additive for this study. It is an organic based black liquid at room temperature. Based on the elemental analysis results, it contains carbon, nitrogen, hydrogen, sulphur and some other components, which warrant a further investigation.

\section{Effects on the binders rheology properties}

The viscosities of AC 80/100 and SBS binder with different amount of additive at various test temperatures are plotted in Figures 2(a) and 2(b), respectively. From these graphs, as expected, it is clear that viscosity decreases significantly as the test temperature increases. This is due to the effect of higher temperature to increase the average kinetic energy between the binder molecules. The viscosity of the AC $80 / 100$ asphalt binders with additive reduces as concentration of additive increases. It means that higher concentration of additive (3\%) improves the performance of this asphalt binder.

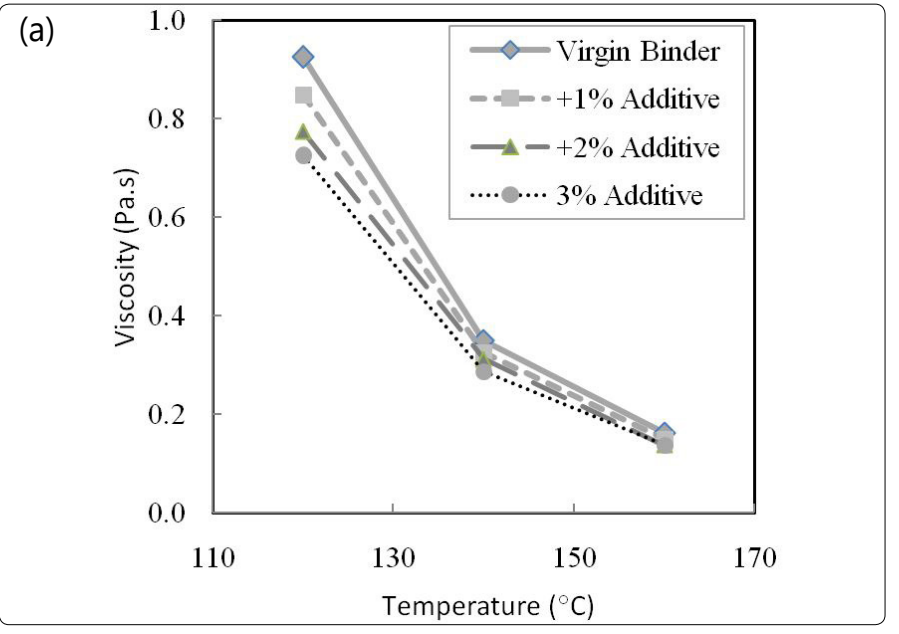

(b)

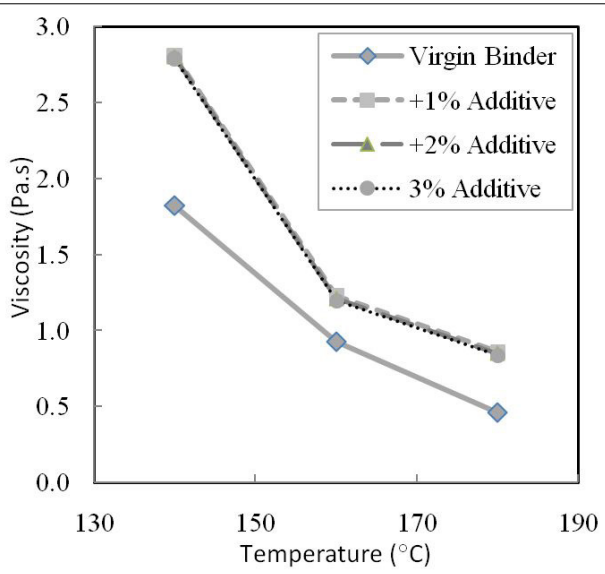

Figure 2. Viscosity of (a) AC 80/100 and (b) SBS binder with RPB additive at different temperatures. 
Figure 2(a) also shows that, for AC 80/10 binder with additive, viscosity reduction decreases with the temperature. The highest viscosity reduction was observed at $120^{\circ} \mathrm{C}$. Then, viscosity reduction was found to decrease at $140^{\circ} \mathrm{C}$ compared to that at $120^{\circ} \mathrm{C}$. Basically, viscosity reduction was not significant at $160^{\circ} \mathrm{C}$. On the other hand, SBS asphalt binder with residue additive showed an increase in viscosity after adding the additives. This might be due to incompatibility between the additive and the SBS asphalt binder. Addition of additive molecules into SBS was likely to increase the internal friction forces of the binder which caused the molecules to move less freely and resulted an increase in the viscosity. Due to the negative effects of the additives in SBS binder in terms of the viscosity, which is the most important property that should be reduced during the mixing, this binder had not been further studied in the DSR test.

For asphalt pavements, rutting is one of the most serious forms of pavement distress, and severe rutting is a cause of pavement failure. DSR was used to evaluate the Superpave rutting properties of AC 80/100 binder containing different additive contents. Higher ratio value of Complex Modulus to phase angle $\left(G^{*} / \sin \delta\right)$ indicates higher rutting resistance of the asphalt binder. Figure 3 shows the $\mathrm{G}^{*} / \sin \delta$ of asphalt binder with $1 \%, 2 \%$ and $3 \%$ additive from $46^{\circ} \mathrm{C}$ to $82^{\circ} \mathrm{C}$. From the figure, asphalt binder rutting resistance reduces very little when additive was blended into the asphalt binder. Increasing additive content slowly increases $G * / \sin \delta$, while increasing test temperature reduces $\mathrm{G}^{*} / \sin \delta$.

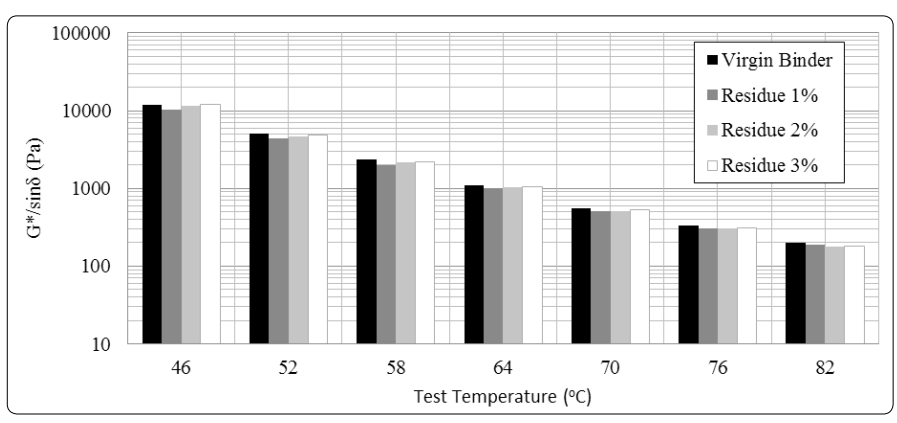

Figure 3. $\mathrm{G}^{*} / \sin \delta$ of $\mathrm{AC} 80 / 100$ binder containing $1 \%, 2 \%$ and $3 \%$ RPB additive.

Figure 4 shows the relationship between $G^{*}$ and phase angle ( $\delta$ or delta) versus test temperature of $A C 80 / 100$ asphalt binder with and without additive. From the results, $\mathrm{G}^{*}$ reduces when test temperature increases. Generally, there is no obvious influence of this additive on the $G^{*}$ and $\delta$ for the used binder.

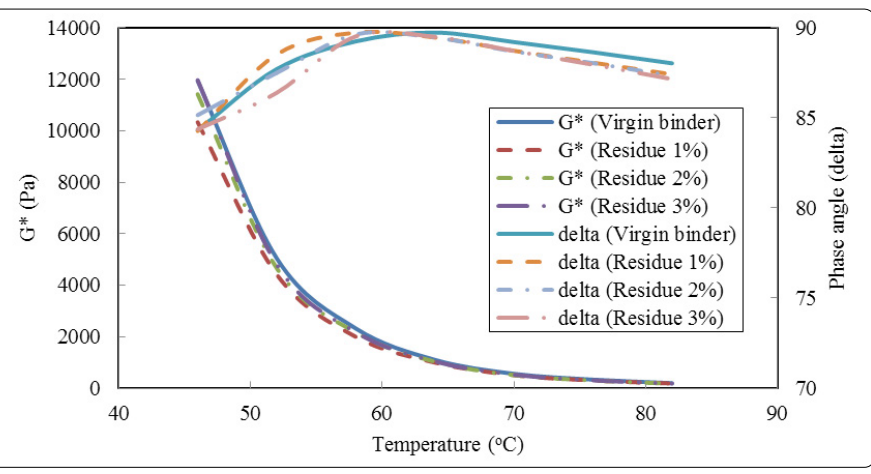

Figure 4. Relationship between $\mathrm{G}^{*}$, phase angle (delta) and test temperature of AC 80/100 binder with different amount of RPB additive.

\section{Effects on asphaltenes content of the binders}

Asphalt or heavy oil is generally constituted of oil, resin and asphaltene. The two heavy and polar components of heavy oil are asphaltenes and resin [17]. Asphaltenes are the highest molecular weight compounds with aromatic rings structure, some side chains and carbon/hydrogen ratio less than 0.8 [18]. Asphaltenes influence the viscosity of heavy oil greatly but resins reduce the influence of asphaltenes on viscosity [17]. From previous studies, it was reported that the chemical structures, physicochemical properties and volume fraction of asphaltenes are the main factors that influence the viscosity of the heavy oil [19]. Viscosity of heavy oil increases with the increase of asphaltenes content. This is due to the strong aggregation of asphaltenes particles. Therefore, reduction of asphaltenes content can be another alternative to reduce viscosity of the binder.

Figure 5 shows the asphaltenes content of a series of binders. By comparing the asphaltene contents between AC80/100 binder and SBS binder, the asphaltenes content of SBS binder (50.4\%) was much higher than that of AC80/100 binder (27.8\%). The result deduced directly that SBS has higher viscosity at room temperature compared to AC 80/100. Therefore, higher temperature is needed during the mixing of the SBS binder with aggregates. Nevertheless, there were only little changes in the asphaltene content for AC 80/100 with $1-3 \%$ of RPB without a clear trend. On the other hand, for SBS binder, asphaltenes content reduced little when additive content increased from 1 to $3 \%$. However, the viscosity of SBS binder with RPB as additive did not reduce as expected.

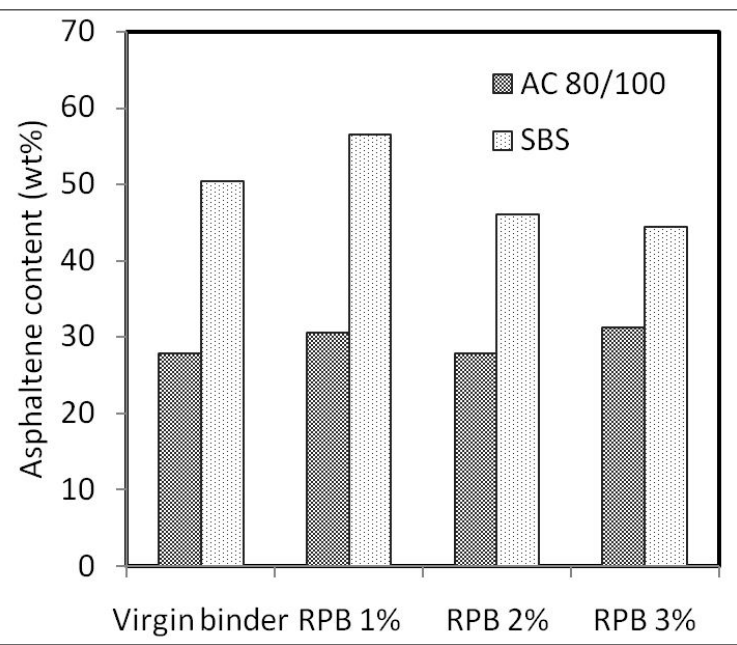

Figure 5. Asphaltenescontentof AC 80/100 and SBS binder containing RPB.

Gel Permeation Chromatography of the binders with RPB as additive were also carried out but the result was inconclusive (not shown) for the mix material. There were only slight reduction in the average molecular weights and the effect of the additive was not significant on the changes in distribution of values for large molecular sizes (LMS), medium molecular sizes (MMS) and small molecular sizes (SMS) [20]. According to Kim et al [8]., viscosity of asphalt binder is related to the amount of large molecular size molecules. However, the phenomenon was not observed here. Further investigation is necessary. 


\section{Conclusions}

RPB, a liquid organic residue from pyrolysis was tested as a warm mix additive in asphalt binders. Its influences on the chemical and rheological properties of two conventional asphalt binders in Malaysia were investigated. Viscosity test, DSR, GPC and asphaltenes content analysis were carried out in this research. This additive showed an acceptable viscosity reduction for $A C 80 / 100$ binder and not for SBS binder. Meanwhile, the effect of RPB on reducing the viscosity of $A C$ $80 / 100$ at lower test temperature is higher when compared to higher test temperatures. The viscosity reduction was also found to increase with the additive concentration for $A C$ $80 / 100$ in the current study. RPB has not showed any negative effect on rutting resistance of binders. With the acceptable viscosity reduction and without negative effect on the rutting resistance, RPB was found a potential warm mix additive for AC 80/100 asphalt binder in Malaysia.

\section{Acknowledgment}

The authors acknowledge the Universiti Sains Malaysia Short Term Grant(304/60312033) for carried out the project.

\section{References}

1. Rubio MC, Martinez G, Baena L, Moreno F. Warm Mix Asphalt: An Overview. Clean Prod J.2012; 24: 76-84. doi: 10.1016/j.jclepro.2011.11.053

2. Prowell BD, Hurley GC, Frank B. Warm Mix Asphalt: Best Practices. 3rd edition.Lanham, MD: National Asphalt Pavement Association; 2012.

3. EAPA. The used of Warm Mix Asphalt. European Asphalt Pavement Association (EAPA). Accessed February20, 2017.

4. Jamshidi A, Golchin B, Hamzah MO, Turner P. Selection of type of warm mix asphalt additive based on the rheological properties of asphalt binders. Clean Prod J. 2015; 100: 89-106. doi: 10.1016/j.jclepro.2015.03.036

5. Hamzah MO, Teh SY, Golchin B, Voskuilen J. Use of imaging technique and direct tensile test to evaluate moisture damage properties of warm mix asphalt using response surface method. Construction and Building Materials. 2017; 132: 323-334. doi: 10.1016/j.conbuildmat.2016.11.092.

6. Kakar M, Hamzah M, Valentin J, Hasan M. Mixture and rheological performance of asphalt binders blended with cecabase warm mix additive. 27th ARRB Conference, Melbourne, Victoria, Australia,2016.
7. Gungat L, Yusoff NIM, Hamzah MO. Effects of RH-WMA additive on rheological properties of high amount reclaimed asphalt binders. Construction and Building Materials. 2016; 114: 665-672. doi: 10.1016/j. conbuildmat.2016.03.182.

8. Kim Y, Lee J, Baek C, et al. Performance Evaluation of Warm-And HotMix Asphalt Mixtures Based on Laboratory and Accelerated Pavement Tests. Advances in Materials Science and Engineering. 2012; 901658: 9. doi: $10.1155 / 2012 / 901658$.

9. Zaumanis M. Warm Mix Asphalt Investigation. PhD Thesis, Riga Technical University, Kgs. Lyngby, Denmark; 2010.

10. Croteau JM, Tessier B. Warm mix asphalt paving technologies: A road builder's perspective. Paper presented at Annual Conference of the Transportation Association of Canada, Toronto, Ontario, 2008.

11. Bueche N. Warm Asphalt Bituminous Mixtures with Regards To Energy, Emissions and Performance. Young Researchers Seminer (YRS) LAVOCCONF-2010-002, Torino, Italy. 2009.

12. Liu JK, Gunning HE. Syncrude Analytical Methods Manual for Bitumen Upgrading. Alberta oil Sands Technology and Research Authority, Edmonton, Alberta; 1991.

13. Lee SJ, Amirkhanian SN, Park NW, Kim KW. Characterization of warm Mix Asphalt Binders Containing Artificially Long-Term Aged Binders. Construction and Building Materials. 2009; 23(6): 2371-79. doi: 10.1016/j. conbuildmat.2008.11.005.

14. Yildirim Y. Polymer Modified Asphalt Binders. Construction and Building Materials. 2007; 21(1): 66-72. doi: 10.1016/j.conbuildmat.2005.07.007.

15. Tia M. Fundamentals And Practice Of Asphalt Mixture Design Procedures To Assure Adequate Performance. 13th conference on pavement engineering, Hsin Chu, Taiwan, 2005.

16. Altgelt $\mathrm{KH}$. Composition and Analysis of Heavy Petroleum Fractions. New York, NY: Marcel Dekker; 1993: 129-132.

17. Pierre C, Barré L, Pina A, Moan M. Composition and Heavy Oil Rheology. Oil \& Gas Science and Technology. 2004; 59(5): 489-501. doi: 10.2516/ ogst:2004034.

18. Wei J, Shull JC, Hawley MC, Barak J. Characterization of Asphalt Binders Based on Chemical and Physical Properties. International GPC symposium '94, 95-0365. 1994: 729-756.

19. Luo P, Gu Y. Effects of asphaltene Content on the Heavy Oil Viscosity at Different Temperatures. Fuel. Elsevier J. 2007; 86(7-8): 1069-1078. doi: 10.1016/j.fuel.2006.10.017.

20. Ragab M, Abdelrahman M. Investigation of the Physical and Molecular Properties of Asphalt Binders Processed with Used Motor Oils. Journal of Materials. 2015; 632534: 9. doi: 10.1155/2015/632534. 